\title{
A patient with Graves' disease, thrombocytopenia and chronic hepatitis $B$
}

\author{
CC Szeto, CC Chow, GTC Ko, KY Li, VTF Yeung, CS Cockram
}

\begin{abstract}
Summary
A 22-year-old Chinese man, a HBsAg carrier, presented with relapse of thyrotoxic Graves' disease complicated by thrombocytopenia and hepatitis. Platelet count and liver enzymes gradually improved following successful treatment of the thyrotoxicosis with radioactive iodine. Possible pathogenetic links and therapeutic implications are discussed.
\end{abstract}

Keywords: thyrotoxicosis, thrombocytopenia, chronic hepatitis

A 27-year-old Chinese man first presented in 1990 with thyrotoxic symptoms and goitre. He was a known HBsAg carrier with no risk factors and normal liver enzymes and biopsy. Hepatitis e antigen ( $\mathrm{HBeAg}$ ) was also positive. Thyroid-stimulating hormone was less than $0.02 \mathrm{mIU} / 1$ (normal $0.3-4.0$ ), serum free triiodothyronine $22.3 \mathrm{pmol} / 1$ (normal 3.38.2). Serum free thyroxine was not checked. Thyroid antimicrosomal and antithyroglobulin antibodies were negative. Graves' disease was diagnosed and he was treated with propylthiouracil with good response. Propylthiouracil was continued for 18 months. His platelet count was $110 \times 10^{9} / 1$ (normal $140-380$ ) at that time.

The patient developed thyrotoxic symptoms again in early 1994. Serum thyroid-stimulating hormone concentration was $0.07 \mathrm{mIU} / 1$, serum free thyroxine concentration was $34.7 \mathrm{pmol} / 1$ (normal 10.2-19.6). Propylthiouracil was restarted. Six weeks later he developed itchiness and nausea. Liver function tests showed an alanine transaminase of $874 \mathrm{IU} / 1$ (normal 0-58), alkaline phosphatase of $128 \mathrm{IU} / 1$ (normal 35-105), bilirubin $8 \mu \mathrm{mol} / 1$ (normal $0-15$ ), and platelet count was $110 \times 10^{9} / 1$. Serum free thyroxine concentration was $12.2 \mathrm{pmol} / 1$. Propylthiouracil was stopped for possible drug-induced hepatitis. Alanine transaminase fell to $139 \mathrm{IU} / 1$ within a month. Radioactive iodine $(8 \mathrm{mCi})$ was given in June, 1994. However, the serum free thyroxine concentration rose further to $167 \mathrm{pmol} / 1$ in August and he remained clinically thyrotoxic.

Lithium carbonate $400 \mathrm{mg}$ bid was started as temporary antithyroid treatment. Serum free thyroxine concentration decreased to $50.9 \mathrm{pmol} / 1$ three weeks later, but rose again to $99.8 \mathrm{pmol}$ after two months. He developed nausea and abdominal discomfort again. A rise

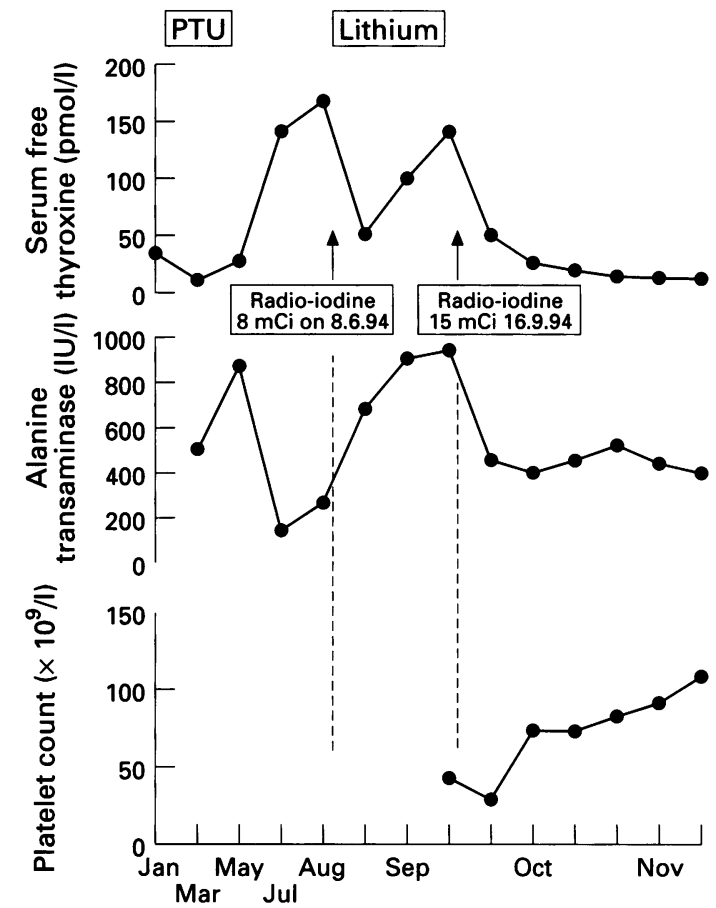

Figure 1 Sequential changes in serum free thyroxine concentration, platelet count and alanine transaminase concentrations. PTU=propylthiouracil

in alanine transaminase to $911 \mathrm{IU} / 1$ was noted, with normal alkaline phosphatase and bilirubin levels, while his platelet count fell to $62 \times 10^{9} / 1$ (figure 1). Lithium was stopped. Alanine transaminase rose further to $1059 \mathrm{IU} / 1$ and platelet count fell to $10 \times 10^{\%} / 1$. Peripheral blood smear, clotting profile and abdominal ultrasound were unremarkable. He remained sero-positive for $\mathrm{HBsAg}$ and $\mathrm{HBeAg}$. IgM antiHAV, anti-HCV, anti-smooth-muscle, antimitochondrial, antinuclear and anticardiolipin antibodies were negative. Serum vitamin B12 and folate levels were normal. Bone marrow was reactive.

He developed recurrent epistaxis and gum bleeding. Repeated platelet transfusion was required. Five doses of intravenous gammaglobulin were given without effect. He received $15 \mathrm{mCi}$ radioactive iodine in mid-September. Symptoms improved substantially and serum free thyroxine concentration fell to $25.5 \mathrm{pmol} /$ 1 within four weeks. Platelet count rose to $72 \times 10^{9} / 1$, and alanine transaminase fell to $399 \mathrm{IU} / 1$. By November, the patient was totally asymptomatic. His platelet count was $112 \times 10^{9} / 1$, alanine transaminase was $315 \mathrm{IU} / 1$ and serum free thyroxine concentration was 
$7.7 \mathrm{pmol} / 1$. Replacement thyroxine was commenced. A summary of the biochemical changes are represented in figure 1.

\section{Discussion}

This case demonstrates possible interactions between thyrotoxicosis, thrombocytopenia, and chronic active hepatitis (figure 2). Either an immunological or a metabolic mechanism may account for the coexistence of these conditions.

While the first hepatitis episode was probably propylthiouracil-related, the second one was not. Hyperthyroidism per se has been reported to cause liver enzyme abnormalities, ${ }^{1}$ mostly elevation of alkaline phosphatase. A hepatic picture in thyrotoxicosis is also possible, even without coexisting liver disease. Our patient was $\mathrm{HBeAg}$ positive, suggesting active viral replication. It has been suggested that patients with Graves' disease have genetically determined immunological fragility which may predispose to viral hepatitis. ${ }^{2}$ We have not observed such a phenomenon, although both conditions are common in our locality. We are also unaware of previous reports of autoimmune thyroid diseases triggered by chronic hepatitis B.

The association between thyrotoxicosis and thrombocytopenia was first reported 60 years ago. ${ }^{3}$ About $40 \%$ patients with untreated thyrotoxicosis have a low platelet count. ${ }^{4}$ An autoimmune process was first suggested, although nonimmunologic mechanisms are now more generally accepted.,6 Kurata and co-workers ${ }^{5}$ found that platelet survival was decreased in rats injected with triiodothyronine. They suggested that thyrotoxicosis could activate the reticuloendothelial system and hence cause platelet sequestration.

The cause of thrombocytopenia in our patient was not clear. Its response to radioactive iodine but not immunoglobulin suggest

1 Fong TL, McHutchison JG, Reynolds TB. Hyperthyroidism and hepatic dysfunction: a case series analysis. $\mathcal{F}$ Clin Gastroenterol 1992; 14: 240-4.

2 Mancini A, De Marinis L, Fiumara C, et al. Ruolo dei meccanismi autoimmuni nella sindrome ipertiroidismoepatite virale: una possibile non casuale associazione. Revisione della leteratura e casistica personale. Minerva Med 1990; 81: 249-54.

3 Jackson AS. Acute hemorrhagic purpura associated with exophthalmic goiter. $\mathcal{F} A M A$ 1931; 96: 38-9.

4 Hymes K, Blum M, Lackner H, Karpatkin S. Easy bruising, thrombocytopenia, and elevated platelet immunoglobulin G in Graves' disease and Hashimoto's thyroiditis. Ann Intern Med 1981; 94: 27-30.

5 Kurata Y, Nishioeda Y, Tsubakio T, Kitani T. Thrombocytopenia in Graves' disease: effect of T3 on platelet kinetics. Acta Hematol 1980; 63: 185-90.

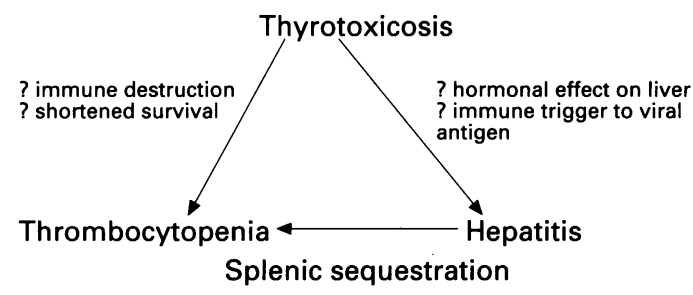

Figure 2 Pathogenetic interaction of coexisting thyrotoxicosis, hepatitis and thrombocytopenia

\section{Learning points}

- thrombocytopenia associated with thyrotoxicosis may be due to coexisting immune destruction or, more commonly, shortened platelet survival due to nonimmune mechanisms

- in this case, the thrombocytopenia will usually subside after the thyrotoxicosis has been controlled. Splenectomy should not be considered until the patient is rendered euthyroid

- flare-up of hepatitis may be induced by thyrotoxicosis, and effective control of the latter condition may help the remission of hepatitis

nonimmunologic mechanisms. Folate deficiency and antiphospholipid antibody syndrome were excluded. Platelet-specific immunoglobulin was not measured. Its value in diagnosis is, however, doubtful. ${ }^{7}$ Active hepatitis may also cause splenic sequestration. The choice of therapy for thrombocytopenia in our patient was difficult. Intravenous immunoglobulin failed. Glucocorticoid was contraindicated because of active hepatitis. Since thyroid ablation has been reported to lead to recovery of the thrombocytopenia, ${ }^{8-10}$ we elected to give radioactive iodine therapy before pursuing other possibilities.

6 Panzer S, Haubenstock A, Minar E. Platelets in hyperthyroidism: studies on platelet counts, mean platelet volume, 111-indium-labeled platelet kinetics, and platelet-associated immunoglobulins G and M. F Clin Endocrinol Metab 1990; 70: $491-6$.

7 Handin RI. Disorders of the platelet and vessel wall. In: Isselbacher KJ, Braunwald E, Wilson JD, Martin JB, Fauci Isselbacher KJ, Braunwald E, Wilson JD, Martin JB, Fauci 13th edn. New York: McGraw-Hill Inc, 1994.

8 Adrouny A, Sandler RM, Carmel R. Variable presentation of thrombocytopenia in Graves' disease. Arch Intern Med 1982; 42: $1460-4$.

$9 \mathrm{Ma} \mathrm{MX}, \mathrm{Yu}$ JR, Cai ZQ. Clinical analysis of 36 cases of coexistent hyperthyroidism with idiopathic thrombocytopenic purpura. Chung Hua Nei Ko Tsa Chih 1989; 28: 136-8. 10 Liechty RD. The thyrotoxicosis/thrombocytopenia connec-
tion. Surgery 1983; 94: $966-8$. 